\title{
As famílias e a CLASSE ESPECIAL EM UM COLÉGIO de ELITE
}

THE FAMILIES AND SPECIAL CLASSES IN SCHOOL OF ELITE

\author{
AdarzilseMazzuco DALLABRIDA ${ }^{1}$
}

RESU M O : o presentetrabal ho aborda as expectativas familiares na escolha de um colégio privado econfessional que atende à el ite catarinense há mais de um século. Os dados foram col etados através deentrevistas eanál ise documental. Os principais resultad os apontam que as famílias foram buscar nesta institui ção um atendimento mais escolarizantee, a escola, desacreditando no potencial de aprendizagem dos conteúdos escolares destes alunos, buscava implementar atividades de vida diária. Concluiu-se que essas famílias travaram uma luta contra a exclusão de seus fil hos nos espaços destinados aos não-deficientes, abriram caminhos para que estes filhos pudessem percorrer suas trajetórias de vida dentro do padrão queel es al mejavam.

PALAV RAS-CHAVE: educação especial; deficientemental; escolarização; família.

\begin{abstract}
A BSTRACT: the present study presents family expectations about the choice of a private school of religious orientation that has catered to the elitein the state of Santa Catarina for over a century. The data was collected by means of interviews and documentary analysis. The main results show that the families enrolled their children with disability in this school, expecting academic services from the institution, while the school underestimated the students' learning potential and proposed instead a program of daily living skills. We concluded that these families put up a fight against the exclusion of their children from places open exclusively to non disabled individuals, so as to create new possibilities their children could follow that were compatible with family expectations.
\end{abstract}

KEYWORDS: special education; disability; education; family.

\section{InTROdUÇÃo}

Nesteartigo pretende-seapresentar uma partedos principais resultados relativos à família realizada na tese de doutoramento intitulada “As famílias com filhos deficientesea escolha daescola", deminhaautoria, queanalisa as motivações e expectativas das famílias que sel ecionaram um colégio confessional, localizado em Florianópolis, capital do Estado deSanta Catarina, para proporcionar educação formal a seus filhos considerados com deficiência, entreas décadas de 1970 a 1990, bem como, a forma como esta instituição educacional, naquelemomento histórico, organizou-se para atender estes alunos.

A construção dos objetivos parte da premissa de que a sociedade, através das exigências e momentos históricos, é a responsável por identificar, classificar econstruir classes de indivíduos, segundo sua funcionalidade, com base

${ }^{1}$ Universidade do Sul deSanta Catarina-UNISUL.E-mail: Ize.Dallabrida@unisul.br 
nos comportamentos sociais estabelecidos como legítimos. A pesquisa tem como embasamento teórico autores que já desenvolveram trabal hos nesta concepção, como Bueno (1993, 1997, 2001), Crochik (1995) eGoffman (1988), equeestabeleceram discussão, de forma ampla e crítica, em que procuraram ultrapassar a simples determi nação eclassificação das deficiências, mas tecem seus recortes como produto deuma construção social.

Partindo do pressuposto de que o conceito de deficiência é uma construção social, para além das determinações biológicas, ou seja, de que a deficiência orgânica não se constitui na única característica para a produção da identidade dos sujeitos, mas sim que, sem negar estas características, são marcas fundamentais na construção dessas identidades, não pode prescindir dos processos sociais pelos quais eles passam esão fatores determinantes para a sua humanização.

Bueno (2001) discute como a "anormalidade enquanto manifestação concreta" seapresenta nas relações entrehomem emeio. A firma que este conceito foi historicamentese modificando na medida em que o homem foi transformando suas condições sociais. Com relação ao conceito de deficiência mental, explica que ele foi identificado a partir do final do século XVIII, em determinadas formações sociais que exigiam formas específicas de produtividade intelectual.

Crochik (1995 p. 15) discutea noção de preconceito, recorrendo a várias áreas do saber, afirmando que o queleva o indivíduo a ser ou não preconceituoso pode ser encontrado no seu processo de socialização "no qual se transforma e forma enquanto individuo". Este processo só pode ser entendido como fruto da cultura e da história, o que significa "que varia historicamente dentro da mesma cultura eem culturas diferentes". A s marcas da deficiência podem ser analisadas não somente por sua "materialidade" ou "condição social", mas principalmente na maneira como a sociedadeincorpora eencaixa essas diferenças em seus padrões denormalidade.

Goffman (1988) investigou diversos fatores ligados ao estigma - um val or negativo atribuído a uma condição existencial - edestacou a visibilidade, o encobertamento e a identidade pessoal em seu estudo sobre a manipulação de identidades deterioradas explicando que "[...] o termo é amplamente usado de maneira um tanto semel hante ao sentido literal original, porém, é mais aplicado à própria desgraça do que a evidência corporal (GOFFMAN,1988, p.11).

Estudos no Brasil sobre as estratégias que as famílias de diferentes estratos sociais utilizam na seleção da escola para o filho (NOGUEIRA, 2002; CARVA LHO, 2004; OLIVEIRA, 2005) vêm apontand o que a articulação famíliaescola é a responsável na produção de sujeitos, ou agentes sociais, para ocupar posições determinadas na sociedade às quais são destinados, indicando diferentes estratégias desenvolvidas, tomando como baseo capital econômico, cultural esocial dessas famílias. 
O problema deste estudo baseia-se na fundamentação teórica em Bourdieu (1998, 2003), procura anal isar as expectativas das famílias com relação à escolaridadedosfilhos considerados deficientes eem quemedida essas expectativas com relação aos seus filhos, deficientes ou não, coincide quando colocados no mesmo ambienteescolar.

Bourdieu (1998) afirma que as classes abastadas colocam em marcha uma série de estratégias, de maneira consciente ou inconsciente, que visam conservar ou aumentar seu patrimônio e, conseqüentemente, manter ou melhorar sua posição social. Entre as principais "marcas de distinção" destacam-se a: linguagem, o vestuário e a escolha da escola de seus filhos. $O$ investimento em educação escolar, ou seja, o pagamento de um colégio que promete "status" intelectual e social e êxito nos graus superiores de educação representa uma "estratégia dereconversão" do capital econômico em capital cultural. Aliás, para o sociólogo francês, os diplomas ecertificados escolares são entendidos como "capital cultural institucionalizado".

Neste sentido, os indivíduos, a partir de sua formação inicial em um dado ambientesocial efamiliar correspondentea uma posição específica na estrutura social, incorporariam um habitus familiar queregeriam suas ações nos mais variados ambientes, como um conjunto de disposições para a ação típica de sua posição, perpetuando assim a estrutura social através desta atual ização constante, porém alerta que este sistema de disposições incorporado pelo sujeito não o conduz em suas ações de modo mecânico. Fala da dinamicidadeentre as condições estruturais originais do sistema de disposições do indivíduo e de sua aplicabilidade no sistema dedisposições da estrutura social: "a estrutura social conduziria as ações individuais e tenderia a se reproduzir através delas, mas esse processo não seria rígido, direto ou mecânico" (NOGUEIRA; NOGUEIRA, 2002, p.04).

Nogueira (2002) apresenta as estratégias de escolarização em famílias deempresários no estado de Minas Gerais, com empresas dos setores diversificados (comércio, indústria, serviços) de porte pequeno a grande, frustrando a intenção inicial deinvestigar somentefamílias deempresas deportegrande(pela dificuldade de identificação e acesso a essas famílias); esta flexibilização, determinada que nem todas as famílias pudessem ser classificadas como ocupando as mais altas posições na escala econômica, porém todos os participantes da pesquisa fazem parte, do que a autora denominou de "classes "superiores". Em suas análises preliminares aponta que a escolha da escola para o filho val or atribuído para o social - estabelecimento quepropiciem a constituição de uma rededesociabilidade - é maior que o valor acadêmico. Explica que neste estudo encontrou um certo desinteresse pelos estudos e uma relação com o conhecimento escolar do tipo "utilitarista", presente de sobremaneira, quando os pais têm baixo nível de escolaridade e creditam seu êxito econômico a competências externas ao conhecimento escolar.". 
Segundo Romanelli, Zago eN ogueira (2000p.12), os principais estudos acerca da relação família e escola têm apregoado que esta relação é complexa e muitas vezes assimétrica com respeito aos valores eobjetivos das duas instituições. Reportam o cuidado com que a família e a escola precisam ser tratadas nas suas condições históricas e socioculturais. E apontam a nova tendência dos estudos sobreas trajetórias escolares, quepassam do acompanhar o percurso para conhecer os diferentes contextos, etapas e mecanismos e modos de constituição da desigual dade como forma de quebra "das grandes regularidades sociais".

No seu trabalho sobre "processos de escolarização nos meios populares", Zago (2000), parte do princípio de que as experiências sociais extraescolares dos alunos precisam ser consideradas em função da leitura do sujeito como parte ativa de seu processo de escolarização. N esse contexto, enfatiza dois pontos como recorrentes: a escola como espaço desocialização e proteção dos filhos do contato com a rua e domínio dos saberes fundamentais para a entrada no mercado detrabalho.

Investigar as motivações e expectativas de famílias que pertencem a classes superiores da sociedade sobre a escolarização de seus filhos deficientes e as formas de organização oferecidas pela a escola escol hida pode oferecer meios para se aprofundar ainda mais a relação entre deficiência, escolarização e classe social, tendo em vista que, nos estudos disponíveis que versam sobre a sel eção da escola pelas famílias, não foram encontrados trabal hos que se reportem à educação especial.

A relatividade entre possibilidades e limites na integração social de indivíduos deficientes, dentro do padrão esperado de determinada sociedade, como por exemplo, escolaridadee atividade profissional, pareceestar relacionada mais com o meio sócio econômico do qual o mesmo faz parte, do quecom as específicas dificuldades que a deficiência poderia ocasionar.

As oportunidades de desenvolvimento da autonomia e da individualidade, que fazem parte do processo dehumanização, são oferecidas de forma desigual através de diversas maneiras de escolarização. Com os deficientes, a "marca negativa" parece suplantada nos estratos superiores da sociedade de classes, pelo fato de terem maior acesso à educação de qualidade e, conseqüentemente, à integração social.

Os estudos sobre família com filhos deficientes têm enfocado mais as percepções ou representações sobre a deficiência e as práticas no processo de escolarização. A discussão atual diz respeito ao processo de exclusão/ inclusão por que passam os considerados "Portadores de Necessidades Educativas "Especiais".

Barroso (2003 p. 27) afirma que são múltiplas as formas de exclusão fabricadas pela escola e aponta quatro modalidades: a escola exclui porque não deixa entrar os que estão fora; a escola exclui porque põe fora os que estão dentro; 
a escola exclui induindo; ea escola exclui porquea inclusão deixou defazer sentido. No primeiro caso aponta a desigualdade de oportunidades relacionada com a origem social dos alunos. No segundo caso, a exclusão refere-se com o fracasso ea evasão dos al unos. Já nas últimas modalidades, a exclusão é sutil, pois ao mesmo momento que oferece seus bancos escolares não estrutura sua prática para quea aprendizagem aconteça, fazendo queo sentimento de pertencimento à escol a não atinja os alunos que possuam diferenças no seu potencial educativo.

A permanência ea naturalização da organização pedagógica, como éa escol a seriada, caracterizada fundamental mente pel a homogeneidade das regras, dos espaços, da divisão do tempo, dos alunos, dos professores e dos processos de incul cação, constitui uma das marcas mais distintivas da cultura escolar. A série, que era inicialmente uma simples divisão de alunos, adquiriu, com a sua legitimação, o papel de medir a progressão dos alunos, tornando-sesinônimo do ano de escolaridade (BARROSO, 2003).

Para além da dicotomia escol a comum ou especial, a discussão que se tenta fazer neste trabal ho tem a pretensão de estabel ecer os parâmetros entre as condi ções objetivas de uma "implicação no funcionamento físico" eas condições reais deinserção destesujeito em seu meio social. A maneira como a nossa sociedade reagiu ecaracterizou as pessoas deficientes ao longo da história possi bilita discutir as formas de escolarização atuais para estes alunos e todo dilema da educação inclusiva que transcende os muros escolares.

\section{Método}

A pesquisa buscou dados das mais variadas formas e fontes, ou seja, mescla entrevistas com as análises documentais - documentos da secretaria do Colégio - ficha de matrícula, planejamento, do Conselho Estadual de Educação, das Leis e decretos, bem como em livros decirculação restrita, encomendados para marcar as comemorações desta Instituição. Foram selecionados seteex-alunos que hoje fazem parte de uma Cooperativa, fundada pelos pais dos alunos que freqüentaram a classe especial no colégio estudado. As entrevistas foram realizadas com seis mães, uma com um pai - cuja esposa já havia sido ouvida - euma com a própria ex-aluna. Em três casos foram realizadas mais de uma entrevista. Também foram entrevistadas três professoras que trabalharam diretamente nas Classes Especiais neste Colégio. No decorrer das análises dos dados foram sendo incorporados ao rol de participantes pessoas que foram sendo indicadas como relevantes para o entendimento da implantação das Classes Especiais.

As questões das entrevistas buscavam mapear a vida em família e escolar destes al unos desdeo nascimento até as expectativas quanto ao futuro. As transcrições das entrevistas foram realizadas por três pessoas, a pesquisadora e dois bolsistas universitários, porém pelo fato de ter o áudio disponível no computador, as entrevistas foram ouvidas e checadas com as transcrições. 
A pós as transcrições eas inúmeras leituras, optou-se por categorizar as falas em três grandes eixos temáticos, separando as falas sobreas famílias esobreo colégio. Em um segundo momento dividiu-se estes eixos em categorias através da constatação de que sobre cada de um deles existia uma gama de informações que precisavam ser sistematizadas. Desta forma, foram construídas ainda subcategorias norteadas pel os objetivos desta pesquisa, na tentativa defocal izar as respostas enão se perder na riqueza do material empírico. No terceiro momento o material foi organizado nos três eixos: as famílias, o colégio e o destino social.

N esteartigo serão apresentados somenteos resultados eas discussões relacionadas ao primeiro eixo.

\section{Resultados e discussão}

As famílias foram classificadas como pertencente as "classes superiores", utilizando-se do conceito deN ogueira (2002), queidentifica esta parcela da população através do "modo de vida" sob a mira dos recursos materiais disponíveis, muito acima da média nacional. Como indicadores foram utilizados: a ocupação e escolarização dos pais e dos irmãos, a condição residencial, apresentada pelo local onde moram, e a posse de residências secundárias $A$ característica principal destas famílias não reside somente na posição social que ocupam atual mente, mas no fato das mesmas terem estu dado em estabelecimentos de ensino privados, e ocuparem esta posição há pelo menos duas gerações.

A segunda residência aparece como opção de casa decampo ede praia, demonstrando que existe nestas famílias a possibilidade de passar as férias dos meses de verão na praia e nas férias dos meses mais frios na casa de campo.

Pinçon ePinçon-Charlot (2002 p.19) relatam a pesquisa realizada sobrea infância dos chefes herdeiros ricos da França e apresentam a relação entre espaço e aprendizagem familiar. Eles evidenciam os elementos da vida cotidiana, entreeles o espaço demoradia:

Parece tão natural que as famílias ricas disponham de grandes apartamentos, de carrões do ano, de palacetes ou propriedades na província, etambém que tenham a possibilidade de viajar pela França e exterior que, natural mente, acabamos esquecendo os efeitos das experiências precoces associadas às experiências em relação à estruturação dos habitus, à formação das predisposições erepresentações queinduzem uma relação específica ao espaço euma relação diferente do corpo, de seu próprio corpo, com o meio circundante "físico" e humano, com a sociedade incorporada nas coisas, inclusive no ordenamento da "natureza" queésempre- pel o menos, na Europa-cultivada, nos dois sentidos do termo.

Estes autores discutem de que forma este enquadramento espacial, convertido aqui na moradia, podeinfluenciar na utilização do corpo enas atitudes sociais das crianças que vivem em espaços amplos e crianças que vivem em espaços pequenos: 
[...] no primeiro caso, o indivíduo dispõe sempre de lugar sendo que a dificuldade consiste em administrar seu corpo, a apresentação de si no meio circundante que coloca em cena, expõe os corpos. Pel o contrário, o al ojamento popular exíguo, adapta-se à displicência das atitudes. No entanto, essas diferenças na experimentação do espaço cotidiano induzem grandes desigualdades no controleulterior das atitudes sociais em quese trata deestar em representação como, por exemplo, tomar a palavra em público, ou simplesmente fazer boa figura em uma reunião (PINÇON E PIN ÇONCHARLOT, 2002, p.19).

A lertam que de nada adiantaria o espaço generoso seo indivíduo não interiorizasse concomitante sua posição ocupada na sociedade, ressaltando quea vida do bairro as benesses eas deferências manifestadas através de bens e serviços inculcam a aprendizagem da vida social e legitimam a superioridade de suas origens.

Em seu estudo sobre um colégio privado da cidade de São Paulo, Almeida (2003) relata quea forma como o endereço era utilizado pela escol a para explicar as propriedades sociais de seus alunos resultava em uma prática de denominação que indicava automaticamente uma posição social inferior, na tentativa de homogenização dos moradores da "zona leste".

Transpondo esta análisepara a partecentral deFlorianópolis, evidenciase que o diferencial é o entorno da avenida Beira Mar Norte, entendida como a parte burguesa da cidade. Nestecaso, encontram-se quatro dos setes participantes com a residência nesteespaço considerado deelitecom padrão apontado por Pinçon ePinçon-Charlot (2002), anteriormentecitados, de amplitude como foi constatado no momento da entrevista, com al to padrão de construção e com um serviço impecável de segurança.

Quanto à formação dos pais, buscou-searticular entrea escolaridadee a ocupação dos pais para construir uma caracterização mais detal hada das famílias, inspirada no trabalho de Nogueira (2003), que estudou a trajetória escolar de universitários pertencentes a famílias intelectualizadas (filhos de professores universitários), fazendo um levantamento dos dados de formação paternos e maternos.

Os dados apontam que em todos os casos encontram-se um dos pais com formação universitária, sendo que em três casos as mães também possuem graduação, porém o que mais chama atenção équetodas as mães estão atual mente dedicadas ao lar, mesmo as que concluíram um curso superior. Sobrea ocupação da mãe, consta quesomenteuma conseguir aposentar-se, ou seja, seguiu sua carréra até o término desua profissão como funcionária pública. Quanto à formação dos outros filhos, aparece à maioria com nível superior, das mais variadas profissões, médicos, advogados, engenheiros, pedagogos, admi nistrador deempresas.

Segundo Carval ho (2004), os estudos nacionais e internacionais têm apontado que o impacto da educação dos pais sobre o desempenho educacional dos filhos pode ser demonstrado pelo nível educacional atingido por estes. Em 
seu estudo sobre estudantes dos Cursos de Engenharia e Direito da PUC-Rio no ano de 2000, os resultados apontaram que a grande mai oria das famílias possuía pais com cursos superiores.

Martin (2002), em seu estudo sobre os modos de educação de jovens aristocratas na França aponta quena N otre-Dame des Oiseaux, escola situada no $16^{\circ}$ bairro de Paris, existe uma forte homogeneidade social no recrutamento das alunas, professoras e religiosas, sendo que muitas gerações da família passam pelo mesmo estabel ecimento de ensino como forma de prolongar a educação familiar.

Brandão e Lelis (2003) em pesquisa desenvolvida sobrea escolarização dos filhos deelites acadêmicas, apontam que existeuma intenção das famílias que os filhos repetissem a trajetória escolar dos pais na rede privada deensino, porém as exceções de filhos matriculados na rede pública foram especificamente em colégios de "excelências" (Colégios de A plicação e Colégio Pedro II), que são disputados por diversas frações das camadas sociais.

No que se refere ao estado civil dos pais, verificou-se que todos foram casados no civil e no religioso, a maioria das famílias possuem ao menos até três filhos, sendo que duas famílias possuem somente um filho.

Aspectos relacionados à composi ção familiar como número e posição na ordem cronológica ocupada pelos filhos em estudos que investigam o investimento das famílias na escolarização têm sido apontados como diferencial. Segundo Nogueira (1991) as estratégi as educativas de família que possuem menos filhos tem sido identificadas de forma diferente, conforme a camada social, nas classes médias e baixas, a aposta tem sido na escolarização do filho mais velho, porém no caso das elites não são encontradas diferenças no modo deinvestimentos entreos filhos, em compensação quanto menor o capital econômico maior o número de filhos e vice-versa.

Neste aspecto, estudos mais recentes têm apontado para o risco da generalização entre as comparações entre o número de filhos das famílias pertencentes às diversas camadas sociais. Ressaltam quea realidade brasileira tem se modificado com os programas de planejamento familiar e com os controles de natalidades (CARVALHO, 2004; OLIVEIRA, 2005).

Segundo os dados da profissão dos pais, não foi possível determinar a renda média familiar, porém infere-se que a mensalidade escolar e todos os atendimentos dispensados ao filho não pesavam no orçamento familiar com base nas informações das entrevistas, a maioria das famílias pagava além da mensalidade do Colégio outros atendimentos clínicos com a renda familiar vinda somente do trabal ho do pai:

[...] às vezes a gente olha para traz - será que a gente fez tudo isto mesmo? Ainda em bom tempo... Por quetudo isto era pago, como diz o $\mathrm{A}$. hojeninguém poderia mais, com salário do jeito que baixou, o poder aquisitivo das pessoas. Graças a Deus! N aquela época o A. trabalhava ainda, hoje ele é aposentado [...] (M-04). 
Destaca-sequenão é somente o capital econômico destas famílias que as faz ir atrás de recursos e atendimentos diferenciados, aqui se aplica o que Bourdieu (apud Nogueira, 2003) comenta sobrea importância de um componente específico do capital cultural queéa informação.

As informações contidas nas entrevistas são suficientes para afirmar que estas famílias possuem recursos e acesso às novas tecnol ogias em casa como computadores (Internet), televisão por assinatura (canal fechado), revistasejornais.

Ao longo do trabalho aparecerá nas falas das famílias a importância queas mesmas del egam a escrita eleitura. N a sociedade "letrada" a escrita ganha val or social em supremacia sobre a oral idadee a alfabetização pode ser vista como parâmetro deexclusão eindusão na sociedadegrafocêntrica, sendo queo anal fabeto éestigmatizado conformemostra Signoroni:

A imagem do analfabeto tem sido associada a "doenças", "males", impedimentos sociais, cegueira, prescrição e, atémesmo, loucura. Isto porque, no imaginário social da nossa civilização, a inteligência está diretamenteligada à escolarização. O não saber significa o vazio, a ausência de luz, o nada, as trevas. $\mathrm{O}$ analfabeto é visto como uma mazela à sociedade, como um nãosujeito, no ditado popular "um zero à esquerda" ( SIGN ORONI (1995 p. 178).

O conjunto das informações sobre a condição de vida das famílias confirma o seu pertencimento às chamadas "classes superiores", correspondendo às descrições deestudos quetrabal haram com estegrupo social (BRANDÃO, 2000; CARVALHO, 2004; NOGUEIRA, 2002 e 2003). Não somente pelo seu capital econômico, mas pelo seu capital escolar, tendo em vista a predominância de familiares com o curso universitário, bem como outros tipos de capitais: o capital social esimbólico, informacional.

Encontrou-se, embora não tivesse sido feita nenhuma questão específica, à vontade dos entrevistados de comentarem sobre o diagnóstico ou a situação de revelação diagnóstica da deficiência.

Observou-sequemuitos dos entrevistados relataram espontaneamente, na tentativa de contextual izar a trajetória do filho, o início da descoberta ou a do momento d.a revelação diagnóstica como al go que marcou a relação com o filho, conformeo relato abaixo:

[...] infelizmente um médico amigo meu J.A.O. quando foi me visitar na maternidade, que o A. pediu, sentou assim como tu estas na minha frente e disse:- não sei andar se vai falar, se vai aprender não se alfabetiza, tudo ele disse. [...] estava sem experiência nenhuma, eu afundei... Fui até o fundo do poço, eu só subi três meses depois. Só chorava, só chorava. [...] Daí quando eu levantei coloquei a $\mathrm{F}$. na minha frente, bem pequenininha assim, nos braços el a estava enrolada em um cobertor, el a tinha três meses de idade, levei para a Fundação para começar a estimulação precoce e dali foi para frente. [...] Não desculpo ele até hoje, ele sabe. [...] se fosse bem meu amigo [...] Como era eé até hoje, eu acho que eu fui contra com o que el e falou... Ele tinha a C. (filha com deficiência), tudo bem atédou as desculpas, mas eu achei atéante... Como a gente diz? Ante pedagógico eu não sei [...] A té hoje eu pego no pé dele, 
quando ele liga, para al guma coisa... Ele ligou esses dias eeu disse:- a F. esta no computador, tem e-mail fez curso na universidade Federal. Eu faço de propósito. Ele diz:- "mas tu és de morte", que a gente tem muita intimidade. Claro A . a gente não diz para as pessoas... Eu sou contra. (M-04).

Neste relato o nascimento do mesmo filho é apresentando permeado as reações desde que o diagnóstico foi dado e comenta o despreparo dos profissionais na área médica "naquela época" sobrea deficiência. A luta travada após a descoberta pareceser um desafio para mostrar queépossível fazer diferente, como aparece na seqüência da fala da mãe que até hojeainda não "desculpou" o médico por as informações iniciais. Neste mesmo sentido encontra-se o relato de outra mãeque, questionada sobrea ocupação do filho, diz:

Porque ele éassim el e não tem Síndrome deDown. Não ele não tem, não tem nada, o problema deleé aprendizado efala, tanto que eu fiz uma ressonância magnética edeu assim, que el etinha umcistozinho, no lado esquerdo epegou a parte intelectual e mais nada. Mas como o médico falou, o neurologista, a senhora, não pode esperar que ele seja um médico ou advogado, mas nada impede que ele seja um bom mecânico, tanto que ele arruma rádio em casa, tudo que estraga lá em casa el earruma. Ele ajudou a pintar móveis queo meu marido comprou. Tudo é o R. lá em casa, só não dá a parte intel ectual. (M-02)

Reiteradas vezes essa mãe volta a mencionar que o filho não tem deficiência mental, queo problema deleédefala ededificuldade deaprendizagem. Parece muito triste quando descreve a diferença entre elee as outras crianças, que nasceram na família na mesma época, pois foi comparando o desenvolvimento deles que procurou investigar o diagnóstico do filho:

Foi assim, quando eu ganhei o R. mais duas irmãs ganharam juntas, eu notava assim que el e era mais ( molengão) e os outros andavam, faziam coisas antes do R.. Só que eu procurava os pediatras eeles diziam: - ah mãeé porqueeleé malandro. Eu dizia: - o R. não quer diálogo, ele não fala, el e aponta. Daí eles falavam: - não, eleémalandro. Sea mãenão der, ele vai pedir, mas a mãe dá, elenão fala. Mas eu notava quetinha al guma coisa errada. Aí com três anos eu procurei a Doutora (?), uma médica pediatra. Daí eu falei para ela. Daí ela disse: - não, tem al guma coisa errada. Aí elas me encaminharam para uma institui ção, acho que tinha fono [...], mas aí el a já me encaminhou, na época eu nem sabia que tinha fonoaudióloga, não sabia, não precisava, imagina há vinte ecinco anos atrás. Daí eu procurei um tal de ( ?) uma clínica quetinha, eu acho que tinha fono, aqui em Florianópol is mesmo. Aí começou minha luta aí, né. Era tudo particular, aí eu pagava fono, psicóloga, sabe. Trabal hei muitos anos com a nossa fonoaudióloga até os 17 anos, aí depois não tava rendendo mais, aí demos um tempo [...] O problema é com a fala, e aprendizado. Mas ele é normal tanto que ele tirou a carteira de motorista e tudo [...] Mas assim, por exemplo, ele escreve tudo se eu ditar para ele, lento. Mas assim, continha dinheiro el e sabe lidar, ele compra faz tudo sabe. (M-02)

É nítido o quanto à mãetenta diminuir a marca da deficiência em sua fala que está carregada de tristeza e de inconformidade pelo "atraso de desenvolvimento" do filho. Carrega sozinha, como veremos mais tarde, a tarefa decuidar destefilho, justificando a ausência do pai como sendo o responsável por pagar as contas, o trabal ho de provedor, mas ressaltando seu papel de intelectual, 
muito distante do potencial do filho. A credito que o relato abaixo ilustra bem o sentimento de todas essas famílias em relação aos diagnóstico do filho:

[...] por que quando nasce um filho, é uma agressão, é uma agressão, quero dizer queessa agressão que a pessoa sente: por que comigo? Por que comigo? Por que não foi com outro. Eu sou tão bom, eu fiz isso, eu fiz aquilo [...] essa agressão que ele tem, eletransforma em uma busca, de cobrir, de empanar um pouco [...] porque quando nasce seu filho você quer que ele seja o mais lindo, o mais bonito, o mais tudo... A gente nunca espera ter um filho deficiente, porquesealguém diz que esta feliz porque o filho nasceu deficiente, para mim não é normal! N inguém quer que seu filho seja, embora a gente goste, ame, a gente nunca quer. (P 04)

Nestes relatos observa-se que existeum grande desconhecimento sobre as questões que envolvem o nascimento de um filho com deficiência, desde a etiologia, os atendimentos médicos epara-médicose, principalmente, o que envolve prognóstico. O momento da revelação diagnostica é descrito como algo penoso que marca decididamente os encaminhamentos tomados. Uma das mães contou que não amamentou o filho, pois fora orientada na maternidade que não seria possível esuas palavras parecem carregadas de muita "culpa" por aquilo quenão pode oferecer natural mente para um filho esperado por falta de orientação.

A história da educação especial na civilização ocidental apresenta em diferentes épocas que os atendimentos as pessoas com deficiência variaram, mas somente agora, muito recentemente, é que a concepção sobre a deficiência passa ser vista como ol hos educacionais. A visão dínica queperdurou por longas décadas equeainda subsisteem muitas formas de atendimento atualmente, provavelmente foi uma das responsáveis por desencadear enatural izar a necessidade detratamento como se a deficiência fosse uma doença, neste sentido as famílias desses alunos que freqüentaram as classes especiais deste colégio não saíram ilesas e procuraram por anos "tratar" as dificuldades dos filhos com atendimentos fonoaudiológicos, fisioterápicos e psicológicos na tentativa de diminuir as "incapacidades" destes no processo de escolarização regular.

Considerando que a maioria das mães tinha mais de um filho, é compreensível que as mesmas tenham abandonado suas carreiras profissionais. Uma delas depois de 10 anos na profissão de advogada, relata que abandonou a carreira para dedicar-se ao filho com S.D. Infere-se que a formação que a mai oria delas tiveram seja também responsável pela abnegação encontrada nestas mulheres queforam formadas para exercerem o papel de "boas mães eesposas", porém esta atitude de ficar em casa só pôde ser efetivada pelo respaldo que a condição financeira propiciou, principalmente na figura do pai, nesta distinção clara dos papéis tradicionais de homem emulher na configuração destas famílias.

Romanelli (2000), escrevendo sobre a autoridade eo poder na família, indica que a organização familiar é um elemento importante na forma como é conduzido o processo de socialização dos "imaturos". Explica que, apesar das mudanças nas últimas décadas da diversi dade na composição e constituições das 
famílias, a família nuclear continua prevalecendo, mas que sua importância transcendeao predomínio estatístico, residindo em seu significado simbólico que a transformou no modelo ideal deordenação da vida doméstica:

Em linhas gerais, esse modelo de família tem como atributos básicos: uma estrutura hierarquizada, no interior da qual o marido/ pai exerce autoridadee poder sobrea esposa e os filhos; a divisão sexual do trabalho bastante rígida, queseparatarefas eatribuições masculinas efemininas; o tipo devínculo afetivo existenteentreos cônjuges e entre esses ea prole, sendo que nesteúltimo caso há maior proximidade entremãe efilhos; o controleda sexual idadefeminina e a dupla moral sexual (ROM A NELLI, 2000 p.75).

Examinando-se as características de composição destas famílias, é possível afirmar quese trata defamílias nucleares, com fortedivisão do papel dos genitores: a mãeresponsável pela vida privada da família, cuidando da casa edos filhos, eo pai da vida pública, buscando fora o sustento da prole.

Entram aqui também os investimentos "naturais" da classe superior em academias de ginásticas, cursos de informática, dança, entre outros que estas famílias costumam fazer para seus filhos e que aqui também é resguardo para o filho com deficiência.

Carvalho (2004) relaciona as atividades extra-escolares com o capital cultural das famílias, apresentando como um investimento das famílias na educação dos filhos os cursos de língua estrangeira.

As atividades freqüentadas pelos filhos destas famílias variam de natação, ballet, aulas deinstrumentos musicais earte. Entende-se queessas aulas extras fazem parte da busca do "ser integral", ou seja, investindo no potencial dos filhos, incentivando que eles tenham contato com uma gama de atividades que não fazem partedo currículo da escola formal enriqueceriam seu repertório cultural econseqüentementeo prestígio e distinção queadvêm do acúmulo destes capitais inacessíveisà maioria da população.

No caso dos atendimentos clínicos enfrentados pelos participantes desta pesquisa, pode-seaproximar aos investimentos familiares para diminuir o fracasso escolar descritos por Lahire(1997).

Soares (2004), discutindo a escolaridadeobrigatória do aluno surdo do ensino regular, afirma que muitas famílias, devido à posição social, optavam por colocar seus filhos no ensino regular em detrimento ao ensino especial izado, porém possi bilitando atendimento clínico e pedagógico extra-escolar:

A política que originou o surgimento de uma rede privada deensino permitiu quevárias crianças que possuíam deficiências freqüentassem o ensino comum. Pela posição social queocupavam, certos pais recusavam o ensino especializado preferindo que seus filhos permanecessem integrado no ensino comum. Essas crianças usufruíam todo atendimento clínico e pedagógico necessário para garantir a sua permanência escolar de forma integrada. (SOARES, 2004 p.50). 
A pesar da autora estar referindo-se especial mente aos alunos surdose atendimentos clínicos específicos, é possível fazer a aproximação com os dados desta pesquisa, onde os pais procuravam compensar as "deficiências" de linguagem, do tônus muscular eoutros, com atendimento paral elo para compensar o que el e estaria usufruindo se estivesse em uma escola especial.

Quanto às motivações e expectativas das famílias quanto à escolha do colégio para o filho com deficiência mental, os depoimentos abaixo corroboram em demonstrar que estas famílias investiram na sel eção da escola para o filho como estratégia dediminuir as marcas da deficiência, eque concepção de que as escolas especiais não eram para eles torna-se evidente, em suas respostas ao questionamento sobre suas escolhas:

[...] o trabal ho na FCEE foi deestimulação precoce...N ão porqueaqueletrabal ho lá... Encerrou não tinha parte pedagógica nada. (E na APAE?) Esta queo A . foi presidente?Também porquecomo el a sealfabetizou el a precisa de mais coisa... Não sei se eles têm agora... Parece que eles têm alguma... Não sei se vão à escola pública, porque a F. nunca andou na APAE. (M-04).

Ai um dia eu estava vindo da APAE e eu vi um menino igual a ele descendo do Coração dejesus deuniforme. [...] Então eu fui saber como équeeles estavam aceitando. Na A PAE el es não estavam alfabetizando, daí era aquele problema, eu queria a alfabetização [...]. (M-03)

Na APAE eles não alfabetizavam... Eu queria a al fabetização para ela. (M-05)

[...] Não, mas eu acho, que no caso do R., não tinha necessidade da APAE, porque eu acho que a APAE a Fundação já não ia aceitar o R., se tu ol har para o R., tu não diz que ele tem problema, nenhum. Não tem assim, tanta dificuldade nas coisas. O problema dele era a aprendizagem e a [...]. Eu não sei se a APAE faz esse trabal ho também, nunca procurei a APAE. (M-02).

Basicamente a expectativa é que o filho, apesar da "deficiência", fosse alfabetizado por ter um "nível mais elevado", como mencionou a última mãe. Demonstram que o relacionamento com a família é tranqüilo, mas que ainda perseguem com reforço escolar que os filhos não "desaprendam" o que conquistaram, mantendo uma luta constante:

[...] porque uma criança assim, sem mentira nenhuma a gente educa 24 horas por dia para el a poder crescer e viver em sociedade como a gente vive. Então Graças a Deus! Eu não tenho assim, problema nenhum com ela, ela sabe se comportar ela, ela agora já esta vindo sozinha das coisas. E agora el a continua com reforço pedagógico, porque uma das mães das meninas que estava no Colégio, mãe da C. ela esta dando reforço pedagógico [...] seela está na TV ela está escrevendo, fazendo historinha sempre, desde pequena, sempre se exercitando, impressionante. A gora não as matérias mesmo, só com a S. que ela tem esse reforço, nas segundas, quartas e quintas-feiras (M-04).

É preciso aceitação dos pais - tem que começar pel a família. A té hoje trabal ho com ela, ela não pode ficar parada... Este é meu erro de dar coisas para ela, hojeela tem pouca iniciativa. Eles (SD) não podem parar nunca tem quesempre ser incentivados.... Precisa trabalhar muito... Ela é independente em casa, ela chega el a dobra a roupa el a aprendeu... Sabefazer um macarrão, salsicha...N o 
final de semana eu faço uma faxina, lavo o cabelo ela não gosta el a diz:- eu já sei. (M-05).

A primeira mãe descreve queé preciso educar vinte quatro horas por dia, referindo-se à filha como uma criança, vem corroborar com os estudos que mostram que a pessoa com deficiência mental é tratada dentro da família como uma eterna criança. (TERRASSI, 1993; DALLABRIDA, 1996).

Neste último depoimento a mãe deixa claro que não acredita na independência da fil ha, embora esta já esteja com 26 anos e ainda continua uma vez por semana fazendo a "faxina no banho". Sua descrição de queas pessoas com SD não podem parar nunca de trabal har no sentido de aprendizagem ou reforço, determina sua concepção que a filha será sempre uma pessoa dependente. Com relação à convivência familiar, diz que tem duas netas (11 e 12 anos) e que ambas se relacionam muito bem com a tia, mas impressiona que este relacionamento, só é possível, pois é assegurado pelas brincadeiras de crianças. Comenta que na infância a filha brincava com uma prima "natural mente" sem quea mesma notasse alguma diferença:

[...] a minha cunhada tinha um a filha da idade da C. e ela ficou sabendo só aos seteanos quea C. eraSD eu sentei eexpliquei para ela. Elas brincavam sempre juntas e ela não tinha notado diferenças, hoje ela é médica ( $M-05)$.

Pode-seinferir queas marcas da deficiência encontram-seentranhadas nas atitudes de proteção e cuidado que esta família descreve para com a filha.

Fernandes (2005) destaca que todos da família são atingidos ao nascimento de um membro deficiente. Lembra que muitos irmãos sentem-se abandonados pelos pais eobrigados a esforçarem para serem fel izes e bril hantesjá que nasceram sem nenhuma deficiência:

Os restantes filhos são, pois, abandonados e, ainda, obrigados a esforçarem-se por serem perfeitos, felizes, brilhantes ea darem aos pais todas as al egrias de que eles foram privados pelo aparecimento do problema. Como se os pais projetassem, nos filhos sãos, a imagem idealizada, do filho perdido. E, ainda, algumas vezes, a indisponibilidade parental (dos dois ou, apenas, deum deles) leva-os a que del eguem num dos filhos as suas funções, o queinduz, na criança parentificada, comportamentos dehipermaturação que mais cedo ou mais tarde podem perturbar o desenvolvimento da sua autonomia (FERN ANDES, 2005p. 27).

No relacionamento dos filhos com os pais encontram-se várias descrições, al gumas mães salientam a presença do pai na educação dos filhos na busca da melhor atendimento, alguns mais abertos outros mais distantes, porém todas tiveram a presença dos maridos em casa, mesmo que na função de provedor:

[...] o pai dela cooperou muito com isto (com a desenvol tura da filha), levava ela a tudo, passeava, levava el a a tudo, a incentiva a namorar...Ela namorava o L. (M-06).

[...] ele foi um pai assim, super bacana, porque a gente não fazia nada, na época, imagina, era tudo muito caro, eu pagava fono, psicóloga, eu pagava 
muita coisa e colégio. [...] el e nunca reclamou de nada, assim: - ah! Porque eu não consigo fazer nada, porque tem que gastar com o R.. [...], mas quando precisava, tinha dúvida de alguma coisa... Ele tava presente, né. Mas não é aquela coisa quenão quisessefazer, é porque eu assumia enão precisava. Mas setivesseal guma dúvida, com certeza el esocorria. [...]: Eu sempre, eu quesou mais, eu queajudava mais, assim, porqueelenão tem muito...Paciência (risos). É, porque no caso, ele já trabalha mais, quase nem dá aula mais, porqueé mais projeto e aluno de mestrado, doutorado, então já não tem mais... Tempo.(M02)

[...] nesseperíodo queela estevelá(CCJ), eu semprefui um pai muito presente, não é fazer propaganda minha, por que em toda e qualquer reunião eu participava. (P-04)

Lahire(1997) apresenta a omissão parental como um mito criado pelos professores que ignoram as lógicas das configurações familiares, inferindo que o comportamento eo desempenho dos alunos estejam diretamente atrelado com o empenho dos pais na educação dos filhos.

Nesta pesquisa pode-se conferir quetodos os pais estiveram presentes nas famílias e que as mães, apesar de ter uma participação mais direta com a educação familiar, semprecontaram com o respaldo dos mesmos. Alguns estudos apontam para a prática comum dos pais de abandonarem suas famílias após o nascimento de um filho com deficiência (TERRRASSI, 1995; MARTINEZ, 1992).

Com relação à expectativa com o filho, os depoimentos demonstram mais preocupação que verdadeiramente uma expectativa com o futuro:

Olha, a minha expectativa real mente é a independência... Então eu acho que hoje na idade queela está para nós o mai s interessanterealmente, sem esquecer aquilo que aprendeu é o trabal ho. A preocupação na idade hoje eles ali com adultos... Uma juventude que a gente cuida muito é a parte sexual deles... Que aí vem os namoros (risos) -ela disse que vai arranjar um namorado- Eu não al imento, o C. (P-06) já era de al imentar, o namorado da filha. Então era uma coisa assim claro que a gente sabe que não é nada... Mas o C. (P-06) fazia questão de falar assim, eu já não falo... Porque a gente não sabe se deixar muito livre o que pode acontecer... Podem querer sair juntos...É uma preocupação sabequeeu tenho não gosto muito dealimentar não. Mastambém não condeno. Digo:- A h, F.vamosfazer amigos, vamos ter amigos, amigos que ébom ter. Tu e o L.não estão semprejuntos. Eu não alimento, mas também por causa disto, quea gentesabe, éuma coisa natural à gentesabe, né? Da natureza humana... No fundo no fundo a gente fica com pena, que a gente sabe que a natureza é a mesma [...] No dia dos namorados saíram um grupo da Cooperativa tiveram no Shopping...(M-04)

A preocupação desta mãe com relação à idade da filha e, conseqüentemente, a sexualidade aparece também em outros depoimentos dos participantes. A passagem da infância para a adolescência edela para a vida adulta gera muitas inseguranças nas famílias, principalmente com rel ação ao futuro eà sexualidade. Alguns estudos mostram que os pais lançam mão de estratégias de infantilização na tentativa demantê-los al heios ao seu próprio desenvolvimento, através do uso de roupas, acessórios, brinquedos e brincadeiras de crianças e 
também através da forma de tratamento: “minha criança, minha lindinha, meu bebê" (FRANÇA RIBEIRO, 2001).

Neste trabalho contata-se que essas famílias assistem seus filhos com muita devoção, com muito carinho, porém queas marcas deixadas pela deficiência turvam suas visões para enxergar o filho real adulto, que apesar de ter um diagnóstico que pressupõe uma "deficiência mental", é uma pessoa, e que já conquistou muito mais, através deatendimentos diferenciados quea família pôde oferecer, do que a maioria da população, principalmente saíram das terríveis estatísticas de anal fabetismo queassola Brasil.

N os depoimentos queseguem encontram-seas motivações quefizeram parte do critério de escolha destecolégio para estefilho, mencionam a tradição do mesmo e as aspirações quanto ao relacionamento social , conforme éabaixo:

[...] então a gente procurou um colégio que, era mais para a satisfação nossa do que deles, pensando bem era isso! Mas também era para el es por que havia um relacionamento [...] Então neste Colégio fomos em busca não diriastatus, mas por uma convivência melhor, o Colégio era mel hor, tinha outras vantagens, vantagens essas que a gente já colocou, convivência com pessoas do mesmo nível social. E essas mi nhas sobrinhas queeram da época del a também estavam no colégio, então deu certo. Enquanto pai a gente tem muito claro isso, talvez seja uma maneira de achar que teu filho não pode estar lá (APAE), porque se disser que ele esta no Colégio Coração de Jesus, a verdade é essa. Estar no Coração, esta em classe especial , esta com o mesmo uniforme, então tudo isso... É uma maneira do pai se satisfazer [...] a gentequer queosfilhos serelacionem dentro do padrão de vida da gente, tudo isso também éimportante. (P-04)

[...] então buscamos no colégio a tradição, esperávamos um desenvolvimento mel hor, tanto queela desenvolveu muito na classe especial. Tanto que a classe especial todas as professoras que estavam na dasse especial eram especializadas em educação especial, então elas integraram com a dança, chegaram a fazer parte da banda do colégio. Então tudo isso foi uma evolução e no caso nós pais, no meu e da E. lógico, tinha muita sensibilidade, gostávamos muito do Colégio, elutávamos muito para isso, tanto quequando chegou à época queo Colégio acabou com a classe especial a gente ficou muito chateado [...] (M-04).

Neste sentido as famílias descrevem que este colégio foi o primeiro a implementar classes especiais para atender alunos, que, devido sua condição de deficientes, não eram aceitos nas classes comuns, sendo elegíveis somente para as escolas especiais. Acreditam que a falta de alternativas de atendimento para as pessoas deficientes deveu-se por duas razões: a desinformação e, conseqüentemente, pela forma como a deficiência era encarada.

Infere-secom basenos depoimentos queas motivações eas expectativas das famílias na escolha deste colégio deveu-se mais pela busca de um estabel ecimento deensino de tradição que oferecesse a oportunidade de convívio com pessoas da mesma origem social, muito mais que a busca de atendimento pedagógico. Na maioria dos casos os filhos já estavam no processo de alfabetização emesmo aqueles não conseguiram sealfabetizar as mães declararam quegostariam que o filho estiveainda freqüentando aquela instituição. 
[...] infelizmente ela não conseguiu eu não deixei fazer (formatura) porque ela não aprendeu nem a ler $A$ importância de escola onde tem pessoas normais, atividade de vida diária. Os amigos são até hoje... Eu acho muito importantes os amigos... M uito importante uma pena queacabou... Se não tivesse acabado ela estaria até hoje lá. (M-06)

[...] N ão, eu acho que não é só pelo status, eu não sei qual éa palavra correta que eu vou te falar, ele quer ver seu filho, ele almeja, ele quer que o filho alcance mai or qualidade de vida, de intelectual idade, de aprendizagem para ele, então el e busca o colégio, da preferência pelo colégio, então é em função disso, opção dele, de ter seu filho, em uma escola particular, dentro de um colégio denível social mel hor, um colégio ondeel es saiam bonitinho, direitinho, alfabetizado, com seu uniforme, eu acho que el eainda busca isso. Eu acho que além para aprendizagem de seu filho, el e ainda busca um status, acho que a maioria pensa assim.[...] então eu vou colocar naquel e colégio, porque assim ele é visto de uma maneira diferente, acho que isso ainda existe. Talvez eu esteja errado, tomara que eu esteja totalmente errado. (P-04).

No depoimento acima é possível visualizar que o que esta família está procurando é a ampliação do capital cultural e social do filho, que pode ser corroborado com os relatos abaixo sobre a questão de socialização como a central nesta escolha do colégio:

[...] ol ha minha expectativa até então, além de reforçar aquele trabalho pedagógico que el a tinha feito até então, era também de social ização, porque era um colégio grande, tinha muita gente, participava de tudo [...] Estavam no conjunto fizeram amigos, fizeram amizades, social ização, estavam no colégio grande e ai na hora do pátio e tinha muitas festividades juntas eram conhecidíssimos dentro do colégio (M-04).

[...] foi importante para a rotina, cumprir horários, hojenão precisa acordá-la para ir trabalhar... Disciplina e o mais importante é ter feito amigos, ter trabalhado em grupos Relacionamento com outros al unos quea família acredita que seja bom "Digas com andas que te direi quem és". (M-05).

[...] época queeleesteveno Colégio era interessantepelas amizades, pelo social, mas também os professores eram muito preparados né. Ele tem boas recordações dos professores Já tinha boa educação, o Coração de Jesus, né. E a gentequeria o mel hor para ele(M-02).

Diante dos relatos das famílias sobre suas expectativas como rel ação ao filho ea sua escolarização épossível traçar um perfil destas famílias com rel ação à escolha do colégio. Todas buscavam nesteestabel ecimento deensino a anulação das marcas da deficiência, embora acreditassem na competência pedagógica do colégio, os critérios de seleção passam mais pelas relações sociais latentes que a freqüência em neste colégio pode ofertar do que o atendimento especializado oferecido nas classes especiais. 


\section{Conclusão}

Concluiu-se que desde o nascimento deste filho, estas famílias estão travand o uma batalha, interna e externamente, na busca de um atendimento que "normalize" a questão da deficiência e encontraram no colégio esta abertura. As motivações e as expectativas das famílias nesta escolha deveu-se mais pela busca de um colégio de tradição que oferecesse a oportunidade de convívio com pessoas da mesma origem social, do que na expectativa com relação às possi bilidades de escolarização dos filhos.

O que se pode concluir desta pesquisa é que essas famílias buscaram, através do ingresso de seus filhos deficientes mentais em escola de alto padrão, algum nível de escolarização, bem como a manutenção de relações sociais que minimizassem os processos de desclassificação de seus filhos, na medida em que, para eles, a deficiência era empecilho de inserção social correspondentes às suas expectativas como pais da elitecatarinense.

\section{ReferênCIAS}

ALMEIDA, A. Ultrapassando o pai: herança cultural restrita e competência escolar. In: NOGUEIRA, M. A.; ROMANELLI, G.; ZAGO, N. Família \& Escola: trajetórias de escolarização em camadas médias e populares. Petrópolis: Vozes, 2003. p.81-97.

BARROSO J. Factores organizacionais da exclusão escolar: a inclusão exclusiva. In: RODRIGUES, D. (Org.). Perspectivas Sobre a inclusão: Da Educação à Sociedade. Porto: Porto Editora, 2003. p. 25-36.

BRANDÃO, Z. Entre questionários e entrevistas. In: NOGUEIRA, M. A.; ROMANELLI, G.; ZAGO, N. (Org.). Família e escola: trajetórias de escolarização em camadas médias e populares. Petrópolis, RJ: Vozes, 2000. p.171-183.

BRANDÃ O, Z.; LELIS, I. Elites acadêmicas e escolarização dos filhos. Educação \& Sociedade, V. 24, n. 83, 2003.

BUEN O, J. G. A inclusão dealunos deficientes nas classes comuns do ensino regular. Temas sobre D esenvolvimento, São Paulo, v. 9, n. 54, p.21-27, 2001.

BUENO, J. G. A produção social da identidade anormal. In: FREITAS, M. C. (Org.). História social da infância no Brasil. São Paulo: Cortez, 1997. p. 163-185.

BUENO, J. G. Educação especial brasileira: integração/ segregação do aluno diferente. São Paulo: Educ, 1993.

CARVALHO, C. P. Projetosfamiliares eformação universitária: diplomas etrajetórias sociais em tempos de crise e gl obalização. Cadernos CRH , Salvador, v.17, p.79-90, 2004.

CROCHIK, J. L. Preconceito: indivíduo e cultura. São Paulo: Robel Editorial, 1995.

DALLA BRIDA, A. M. 0 portador de deficiência mental profunda na concepção da mãe. 146 f. Dissertação (Mestrado em Educação Especial) - UniversidadeFederal deSão Carlos-UFSCar, 1996. 
FERNA NDES, O. M. Irmãos doentes e deficientes. Jornal a Página da Educação, Porto, n.145, p.27, maio 2005.

FRANÇA RIBEIRO, H. C. Sexualidade e os portadores de deficiência mental. Revista Brasileira de Educação Especial, Marília, v.7, n.1, p.11-27, 2001.

GOFFMAN, E. Estigma: notas sobrea manipulação da identidadedeteriorada. Rio de Janeiro: Zahar,1988.

LAHIRE, B. Sucesso escolar nos meios populares: as razões do improvável. São Paulo: Ática, 1997.

MARTIN, M. S. Modos de educação dos jovens aristocratas e suas transformações. In: ALMEIDA, A. M. F.; NOGUEIRA, M. A. (Org.). A escolarização das elites: um panorama internacional da pesquisa. Petrópolis, RJ: Vozes, 2002. p. 29-48.

MARTINEZ, C. M.S.. A tividades ebrincadeir as na vida da criança com problemas na aprendizagem no início dos anos 90: a visão dos pais. São Carlos, 1992. 150 f. Dissertação (M estrado em Educação Especial) - Centro de Educação e Ciências Humanas, Universidade Federal de São Carlos, São Carlos.

NOGUEIRA, C. M. M.; NOGUEIRA, M. A. A Sociologia de Pierre Bourdieu: limites e contribuições. Educação \& Sociedade, Campinas, v. 23, n. 78, p.1-15, 2002b. Disponível em: বhttp:/ / www.scielo.br>. Acesso em: 02 set. 2005.

NOGUEIRA, M. A . A construção da excelência escolar - um estudo de trajetórias feito com estudantes universitários provenientes das camadas médias intel ectualizadas. In: NOGUEIRA, M. A.; ROMANELLI, G.; ZAGO, N. (Org.). Família \& Escola: trajetórias de escolarização em camadas médias e populares. Petrópolis: Vozes, 2003. p.125-154.

NOGUEIRA, M. A. Estratégias de escol arização em famílias de empresários. In: A LMEIDA, A. M. F.; NOGUEIRA, M. A. (Org.). A escolarização das elites: um panorama internacional da pesquisa. Petrópolis - RJ: Vozes, 2002 a. p. 49-65.

NOGUEIRA, M. A.; ROMANELLI, G.; ZAGO, N. (Org.). Família e escola: trajetórias de escolarização em camadas médias e populares. Petrópolis, RJ: Vozes, 2000.

NOGUEIRA, M. A. Trajetórias escolares, estratégias culturais e classes sociais - notas em vista a construção do objeto de pesquisa. Teoria e Educação, Porto Alegre, n. 3, p. 89-112, 1991.

OLIVEIRA, C. G. D iga-me com quem andas ete direi quem és: a escol ha da escola como estratégia de distinção. 2004. 148 f. Dissertação (M estrado em Educação) - Pontifícia Universidade Católica do Rio de Janeiro, Rio de Janeiro, 2005.

PIN ÇON, M.; PIN ÇON-CHARLOT, M . A infância dos chefes - a socialização dos herdeiros ricos na França. In: ALMEIDA, A. M. F.; NOGUEIRA, M. A. (Org.). A escolarização das elites: um panorama internacional da pesquisa. Petrópolis: Vozes, 2002. p. 11-28.

ROMANELLI, G. Famílias de camadas médias e escolarização superior dos filhos - O estudantetrabal hador. In: NOGUEIRA , M. A.; ROM A NELLI, G.; ZA GO, N . F amília \& Escola: trajetórias de escolarização em camadas médias e populares. Petrópolis: Vozes, 2000.

ROMANELLI, G.; ZAGO, N.; N OGUEIRA, M. A. Introdução Família \& Escola: trajetórias de escolarização em camadas médias e populares. Petrópolis: Vozes, 2000 p.9-15. 
SIGN ORINI, I. Letramento e (in) flexibilidade comunicativa. In: KLEIMAN, ÂNGELA, R. (Org.). 0 s significados do letramento. Campinas: Mercado de Letras, 1995. p.161-200.

SOARES, M. A. L. O aluno surdo no ensino regular ea escolaridade obrigatória. R evista de Educação, Campinas, n.16, p.49-60, jun. 2004.

TERRASSI, E. Família do deficiente: aspectos comuns eespecíficos contidos no relato de mães de crianças portadoras de diferentes deficiências. 1993. 98 f. Dissertação (Mestrado em Educação Especial) - Centro de Educação e Ciências Humanas, Universidade Federal de São Carlos, São Carlos, 1993.

Recebido em 02/ 02/ 2007

Reformulado em 10/ 10/ 2007

A provado em 29/ 10/ 2007 